\title{
Tobacco use and associated factors among adults reside in Arba Minch health and demographic surveillance site, southern Ethiopia: a cross-sectional study
}

Befikadu Tariku Gutema ${ }^{1,2^{*}}$ (D), Adefris Chuka ${ }^{3}$, Gistane Ayele ${ }^{1,2}$, Wubshet Estifaons ${ }^{4}$, Zeleke Aschalew Melketsedik ${ }^{4}$, Eshetu Zerihun Tariku', Zerihun Zerdo ${ }^{2,5}$, Alazar Baharu ${ }^{2,6}$ and Nega Degefa Megersa ${ }^{4}$

\begin{abstract}
Background: Tobacco use is one of the world-leading preventable killers. There was a varied prevalence of tobacco use and cigarette smoking across different areas. The aim of the study was to assess the prevalence and factors associated with current tobacco use among adults residing in Arba Minch health and demographic surveillance site (HDSS).

Methods: A community-based cross-sectional study was conducted among adults residing in Arba Minch HDSS in 2017. The estimated sample size was 3368 individuals which were selected by simple random sampling techniques using Arba Minch HDSS dataset. Data collection tools were obtained from the WHO STEPwise. Current use of tobacco, which defined as the current use of smoked and/or smokeless tobacco, was considered as the dependent variable. A binary logistic regression model was used to identify candidate variables for the multivariable logistic regression model. An adjusted odds ratio (AOR) at a $p$-value of less than 0.05 was used to determine a statistically significant association between independent and dependent variables.

Result: The prevalence of tobacco use among adults was 20.2\% (95\% Cl: 18.9-21.6\%). The current use of smoked and smokeless tobacco were $17.1 \%(95 \% \mathrm{Cl}$ : 15.8-18.4\%) and 9.7\% (95\%Cl: 8.8-10.8\%), respectively. The current use of tobacco was significantly associated with sex (female [AOR 0.54; 95\%Cl: 0.42-0.68] compared to men), age group (35-44 [AOR 1.57; 95\%Cl: 1.14-2.17], 45-54 [AOR 1.99; 95\%Cl: 1.45-2.74], and 55-64 [AOR 3.26; 95\%Cl: 2.37-4.48] years old compared to 25-35 years old), physical activity (moderate physical activity level [AOR 0.65; 95\%Cl: 0.440.96] compared with low) and residency (highland [AOR 4.39; 95\% Cl: 3.21-6.01] compared with at lowlander). Also, heavy alcohol consumption (AOR 3.97; 95\% Cl: 3.07-5.12), and Khat chewing (AOR 3.07(95\%Cl: 1.64-5.77) were also associated with the use of tobacco among the study participants.

(Continued on next page)
\end{abstract}

\footnotetext{
* Correspondence: befikadutariku2@gmail.com; befikadu.tariku@amu.edu.et

'School of Public Health, Arba Minch University, P.O.Box 21, Arba Minch, Ethiopia

${ }^{2}$ Arba Minch Health and Demographic Surveillance Site (HDSS), Arba Minch, Ethiopia

Full list of author information is available at the end of the article
}

(c) The Author(s). 2021 Open Access This article is licensed under a Creative Commons Attribution 4.0 International License, which permits use, sharing, adaptation, distribution and reproduction in any medium or format, as long as you give appropriate credit to the original author(s) and the source, provide a link to the Creative Commons licence, and indicate if changes were made. The images or other third party material in this article are included in the article's Creative Commons licence, unless indicated otherwise in a credit line to the material. If material is not included in the article's Creative Commons licence and your intended use is not permitted by statutory regulation or exceeds the permitted use, you will need to obtain permission directly from the copyright holder. To view a copy of this licence, visit http://creativecommons.org/licenses/by/4.0/. The Creative Commons Public Domain Dedication waiver (http://creativecommons.org/publicdomain/zero/1.0/) applies to the data made available in this article, unless otherwise stated in a credit line to the data. 
(Continued from previous page)

Conclusion: Nearly one in five adults used tobacco currently in the study area, which is more than the national reports. Interventions for the reduction of tobacco use need to give due attention to men, older adults, uneducated, poor, and highlanders.

Keywords: Tobacco, Smoked, Smokeless, Health and demographic surveillance site (HDSS), Ethiopia

\section{Background}

Tobacco use is one of the world-leading preventable killers, driving an epidemic of cancer, heart disease, stroke, chronic lung disease, and other non-communicable diseases (NCDs). In addition, it is a major preventable cause of premature death and disease worldwide [1,2]. Globally in 2017, around 1.4 billion people aged 15 years or older use tobacco (1.07 billion smokers and 367 million use smokeless tobacco) and the age-standardized global average prevalence of smoking is 19.2\% [3]. It caused around 8 million deaths a year, with a substantially elevated risk of mortality among adults aged above 45 years [3, 4]. Evidences have shown that in the poorest households in some low-income countries as much as $10 \%$ of total household expenditure is on tobacco $[5,6]$. Tobacco use is an important contributing factor to the global burden of morbidity and mortality [7].

Tobacco use increases the risk of death from many diseases, including ischemic heart disease, cancer, stroke, chronic obstructive pulmonary disease, diabetes, and other fatal and non-fatal diseases [8]. Based on the 2015 mortality burden in Ethiopia, ischemic heart disease and tuberculous are among the leading top five causes of death, which are also tobacco-related diseases [9]. In addition, these diseases (including cardiovascular diseases) were also from the leading top five disabilityadjusted life years in the same year [9]. Smoking prevalence projections for 2025 showed that the prevalence in African will increase to $18 \%$ [10]. In sub-Saharan Africa, smoking prevalence varied widely even between similar countries. Smoking rates are higher among countries in the eastern and southern regions of Africa [11]. In addition to its direct morbidity and mortality on the users, second-hand smoke contributes to more than half-billion death worldwide [12]. According to the World Health Organization (WHO) report, the estimated current tobacco use in Ethiopia is $3.9 \%$ (7.6 and $0.3 \%$ for males and females) in the year 2020 [10]. Reports showed that the prevalence of tobacco use in Ethiopia ranges from 4.1 to $28.0 \%$ [13-16]. For instance, a school-based study at Hawassa and Jimma towns of Ethiopia showed that current cigarette smoking among adolescents was $17.2 \%$ [17]. Also, the daily use of smokeless tobacco was $33.1 \%$ among adult pastoralists in the Borena zone, Ethiopia [18]. Contrarily, in Aleta Wondo, none of the women who participated in the study reported current tobacco use [19]. These reports showed that the prevalence of tobacco use in Ethiopia is varied significantly. However, the country is at risk of the tobacco epidemic given the shift in the tobacco industry towards targeting low- and middle-income countries, particularly Africa, to recruit new users [5].

In 2015, by considering the health and economic effect of tobacco use, Ethiopia also implements the WHO MPOWER policy technical package under the WHO Framework Convention on Tobacco Control [5, 20]. As a result, Ethiopia has made progress on tobacco control in recent years. The Ethiopian parliament passed bills in 2012 and 2019. Under the proclamation of No.759/2012, the advertisement of cigarettes or other tobacco products was prohibited. On top of this, in 2019 (Proclamation No. 1112/2019) the Parliament passed additional law which prohibits smoking and tobacco use in public places, the sale of tobacco products for age less than 21 years, and taxation on tobacco product. However, people continue to die and become sick needlessly, and the costs to society from tobacco use continue to mount [21]. To make the proven tobacco control tools work for citizens' wellbeing, periodic monitoring of tobacco use is important to enrich the country with quality data. In addition, local data is needed to inform proactive contextualized tobacco control intervention [22]. For the prevention of NCDs, identifying the major risk factors is important in assisting the planning, determining public health priorities, and monitoring the long-term interventions. The WHO STEPwise approach to Surveillance (STEPS) of NCDs risk factors is based on a sequential level of surveillance of different aspects of NCDs. It is a method using standardized tools to ensure comparability over time and across locations [23]. For overtime comparability of the surveillance data, Health and demographic surveillance site (HDSS) is considered as an appropriate platform. HDSS is a site of filed for longitudinal follow-up of well-defined primary subjects (individuals, households, and residential units) and related demographic characteristics of a population living in a well-defined geographic area [24]. Hence, the aim of the study was to assess the prevalence and factors associated with current tobacco use among adults residing in Arba Minch HDSS, which was collected based on WHO STEPS approach. 


\section{Methods}

\section{Study design and setting}

A cross-sectional study was conducted to assess the prevalence and factors associated with tobacco use among adults residing in Arba Minch HDSS. Arba Minch HDSS operates in 9 of 29 Kebeles of Arba Minch Zuria District, Gamo Zone of Southern Ethiopia. The administrative town of the district, Arba Minch, found $505 \mathrm{Km}$ South of Addis Ababa. The data was collected from April to June 2017.

\section{Study participants}

The study was conducted among adult population age between 25 and 64 years, who were residing in Arba Minch HDSS. Pregnancy and history of recent delivery (up to 8 weeks) were the exclusion criteria. The sample size was estimated using single population proportion formula with the consideration of one of the risk factors for NCDs (prevalence of hypertension), which was $22.4 \%$ [25], 95\% confidence level (CI), and 5\% margin of error. In addition, 1.5 design effect was considered, and the estimated sample size was 396. Five percent non-response rate and based on the WHO STEPS guideline for sample size calculation, eight groups were considered to have an adequate level of precision for every age-sex estimate [26]. Then the estimated final sample size was 3368. Using the Arba Minch HDSS dataset, a simple random sampling technique was followed to select the study participants.

\section{Data collection tools and procedure}

Tools for collecting socio-demographic information, tobacco and alcohol use, food intake and physical activity were obtained from the WHO STEPwise [26]. The wealth index of the participants was determined based on the ownership of the productive asset and characteristics of the house. Mental stress was assessed using a self-reporting questionnaire (SRQ-20) [27, 28]. Data was collected by Arba Minch HDSS filed workers. Training was given for three days for both data collectors and supervisors. A pre-test was conducted on 2\% (on 68 individuals) of the sample size. Details of its methods have been described elsewhere [29-31].

\section{Variables}

The independent variables include socio-demographic status, physical activity level, and alcohol consumption. Socio-demographic variables included sex, age, residency, religion, ethnicity, marital status, occupational status, educational level, wealth status and altitude. Using the principal component factor analysis, the wealth index was computed and grouped into five [28]. Altitude blow $1800 \mathrm{~m}$, between 1800 to $2400 \mathrm{~m}$, above $2400 \mathrm{~m}$ classified as lowland, midland, and highland, respectively [32]. Using a self-reporting questionnaire (SRQ-20), those scored from 0 to 4,5-12, and above 12 were considered as mild, moderate, and severe mental stress, respectively [27]. The index for questions from the STEPS tool was generated in accordance with the manual. Heavy alcohol consumption was generated based on the individual consumption of alcohol with six or more drinks for men, and four or more for women on a single occasion [33]. Physical activity levels was grouped with average metabolic equivalents-minutes per week below 600 as low, for $600-3000$ as moderate and for above3000 as high activity level [26]. As an outcome variable, the current use of tobacco, which defined as the current use of smoked and/or smokeless tobacco, was considered. In addition, the current use of smoked and smokeless tobacco were analyzed separately.

\section{Data processing and analysis}

Data was entered into EPI-data version 3.1 statistical software and analysis was done by STATA version 14 . All covariates with a $p$-value of less than 0.25 in bivariate analysis were considered for a multivariable logistic regression. To assess the presence of an association between current tobacco use and independent variables, a p-value of less than 0.05 in the final model was considered statistically significant. Variable inflation factors were used to assess the presence of multicollinearity, and the maximum value was 1.71. The goodness-of-fit model was assessed using the Hosmer-Lemeshow test and the $P$-value for current use of (smoked and/or smokeless) tobacco was 0.653 . In addition, the $P$-values for smoked and smokeless tobacco use were 0.112 and 0.067 , respectively.

\section{Results}

Socio-demographic characteristics of the study participants

The total number of participants in the study was 3346 with a response rate of $99.3 \%$. The mean (SD) age was 44.6(11.2) years with nearly equally distributed among age groups and sex. Rural residents (83.7\%), Gamo ethnic $(81.1 \%)$ and married $(87.9 \%)$ were majority of the study participants. The most common occupation was farming which incorporates $53.2 \%$ of the participants. Regarding educational attainment, only $30.3 \%$ attended formal education, with the majority attended only primary education (Table 1 ).

\section{Behavioral characteristics of the study participants}

Majority $(64.3 \%)$ of the study participants involved in high level physical activities. Heavy alcohol consumption was $11.5 \%$. Nearly $2 \%$ of the study participates were chewed khat within 30 days and $4 \%$ had severe mental stress (Table 2). 
Table 1 Socio-demographic characteristics of the study participants (3346) by current tobacco use in Arba Minch HDSS, Southern, Ethiopia

\begin{tabular}{|c|c|c|c|c|c|c|}
\hline \multirow[t]{2}{*}{ Variable } & \multirow[t]{2}{*}{ Categories } & \multirow{2}{*}{$\begin{array}{l}\text { Total } \\
\text { Participants } \\
\text { N (\%) }\end{array}$} & \multirow{2}{*}{$\begin{array}{l}\text { Non- } \\
\text { Current } \\
\text { User } \\
\text { N (\%) }\end{array}$} & \multicolumn{3}{|l|}{ Current Tobacco Use } \\
\hline & & & & $\begin{array}{l}\text { Smoked \& Smokeless } \\
\text { N (\%) }\end{array}$ & $\begin{array}{l}\text { Smoked } \\
\mathrm{N}(\%)\end{array}$ & $\begin{array}{l}\text { Smokeless } \\
\mathrm{N}(\%)\end{array}$ \\
\hline \multirow[t]{2}{*}{ Sex } & Male & $1674(50.0)$ & $1235(46.3)$ & $439(64.8)$ & $368(64.4)$ & $230(70.6)$ \\
\hline & Female & $1672(50.0)$ & $1434(53.7)$ & 238(35.2) & 203(35.6) & $96(29.4)$ \\
\hline \multirow[t]{4}{*}{ Age group } & $25-34$ & $804(24.0)$ & $727(27.2)$ & 77(11.4) & $46(8.1)$ & $51(15.6)$ \\
\hline & $35-44$ & $863(25.8)$ & $710(26.6)$ & 153(22.6) & $120(21.0)$ & $84(25.8)$ \\
\hline & $45-54$ & $845(25.3)$ & $656(24.6)$ & 189(27.9) & $163(28.5)$ & $81(24.8)$ \\
\hline & $55-64$ & $834(24.9)$ & $576(21.6)$ & 258(38.1) & $242(42.4)$ & 110(33.7) \\
\hline \multirow[t]{2}{*}{ Residency } & Rural & $2801(83.7)$ & $2174(81.5)$ & 627(92.6) & $551(96.5)$ & 294(90.2) \\
\hline & Urban & $545(16.3)$ & $495(18.5)$ & $50(7.4)$ & $20(3.5)$ & $32(9.8)$ \\
\hline \multirow[t]{2}{*}{ Marital status } & Unmarried* & $405(12.1)$ & $354(13.3)$ & $51(7.5)$ & $41(7.2)$ & $25(7.7)$ \\
\hline & Married & $2941(87.9)$ & 2315(86.7) & $626(92.5)$ & $530(92.8)$ & $301(92.3)$ \\
\hline \multirow[t]{3}{*}{ Ethnicity } & Gamo & 2713(81.1) & 2088(78.2) & $625(92.3)$ & $546(95.6)$ & 288(88.3) \\
\hline & Zeysie & $290(8.7)$ & $273(10.2)$ & $17(2.5)$ & $6(1.1)$ & $17(5.2)$ \\
\hline & Other** & $343(10.3)$ & $308(11.5)$ & $35(5.2)$ & 19(3.3) & $21(6.4)$ \\
\hline \multirow[t]{3}{*}{ Religion } & Protestant & $2104(62.9)$ & 1992(74.6) & $112(16.5)$ & $53(9.3)$ & $72(22.1)$ \\
\hline & Orthodox & 1054(31.5) & $609(22.8)$ & $445(65.7)$ & 403(70.6) & $245(75.2)$ \\
\hline & Other & 188(5.6) & $68(2.5)$ & $120(17.7)$ & 115(20.1) & $9(2.8)$ \\
\hline \multirow[t]{7}{*}{ Occupation } & Farmer & 1779(53.2) & $1274(47.7)$ & $505(74.6)$ & $446(78.1)$ & 253(77.6) \\
\hline & Daily laborer & $257(7.7)$ & $225(8.4)$ & $32(4.8)$ & $22(3.9)$ & $15(4.6)$ \\
\hline & Merchant & $146(4.4)$ & $134(5.0)$ & $12(1.8)$ & $5(0.9)$ & $7(2.1)$ \\
\hline & Housewife & $914(27.3)$ & 812(30.4) & 102(15.1) & $80(14.0)$ & $36(11.0)$ \\
\hline & Employed at Org & 106(3.2) & $96(3.6)$ & $10(1.5)$ & $5(0.9)$ & $6(1.8)$ \\
\hline & Unemployed & 119(3.6) & 103(3.9) & $16(2.4)$ & $13(2.3)$ & $9(2.8)$ \\
\hline & Other & $25(0.8)$ & 25(0.9) & $0(0.0)$ & $0(0.0)$ & $0(0.0)$ \\
\hline \multirow[t]{3}{*}{ Educational status } & No formal education & 2334(69.8) & $1764(66.1)$ & $570(84.2)$ & $504(88.3)$ & 266(81.6) \\
\hline & Primary school & $768(23.0)$ & $676(25.3)$ & $92(13.6)$ & $60(10.5)$ & $50(15.3)$ \\
\hline & Secondary \& above & $244(7.3)$ & 229(8.6) & $15(2.2)$ & $7(1.2)$ & $10(3.1)$ \\
\hline \multirow[t]{5}{*}{ Wealth Index } & 1st quantile & 1039(31.1) & $868(32.5)$ & $171(25.3)$ & 136(23.8) & $79(24.2)$ \\
\hline & 2nd quantile & $690(20.6)$ & $500(18.7)$ & 190(28.1) & 177(31.0) & 75(23.0) \\
\hline & 3rd quantile & $608(18.2)$ & $483(18.1)$ & $125(18.5)$ & 109(19.1) & 64(19.6) \\
\hline & 4th quantile & $479(14.3)$ & $357(13.4)$ & $122(18.0)$ & $102(17.9)$ & 62(19.0) \\
\hline & 5th quantile & $530(15.8)$ & $461(17.3)$ & $69(10.2)$ & $47(8.2)$ & $46(14.1)$ \\
\hline \multirow[t]{3}{*}{ Altitude } & Lowland & $1510(45.1)$ & 1376(51.6) & 134(19.8) & 71(12.4) & $86(26.4)$ \\
\hline & Midland & $427(12.8)$ & $384(14.4)$ & $43(6.4)$ & $25(4.4)$ & $30(9.2)$ \\
\hline & Highland & $1409(42.1)$ & $909(34.1)$ & $500(73.9)$ & $475(83.2)$ & $210(64.4)$ \\
\hline
\end{tabular}

*Unmarried: include single, divorced, separated and widow; ** Other include Goffa, Wolayta, Amhara

\section{Prevalence of tobacco use}

Six hundred seventy-two (20.1\%) and $382(11.4 \%)$ study participants had a history of use of smoked and smokeless tobacco, respectively. In general, 784 (23.4\%) study participants had a history of tobacco use. Six hundred seventy-seven (20.2\%; 95\% CI: 18.9-21.6\%) adults were current tobacco users. Current use of smoked and smokeless tobacco were 17.1\% (95\%CI: $15.8-18.4 \%)$ and 9.7\% (95\%CI: $8.8-10.8 \%)$, respectively. From total study participants, $6.6 \%$ (95\%CI: 5.8-7.5\%) were currently used both smoked and smokeless tobacco.

Out of current smokers, $88.1 \%$ were smoking daily. Of current smokers, 441 (65.1\%) recalled their age at smoking initiation. The mean (SD) age of smoking initiation 
Table 2 Behavioral characteristics of the of the study participants $(N=3346)$ by current tobacco use in Arba Minch HDSS, Southern, Ethiopia

\begin{tabular}{|c|c|c|c|c|c|c|}
\hline \multirow[t]{2}{*}{ Variable } & \multirow[t]{2}{*}{ Categories } & \multirow{2}{*}{$\begin{array}{l}\text { Total } \\
\text { Participants } \\
\text { N (\%) }\end{array}$} & \multirow{2}{*}{$\begin{array}{l}\text { Non- } \\
\text { Current } \\
\text { User } \\
\mathrm{N}(\%)\end{array}$} & \multicolumn{3}{|l|}{ Current Tobacco Use } \\
\hline & & & & $\begin{array}{l}\text { Smoked \& Smokeless } \\
\mathrm{N}(\%)\end{array}$ & $\begin{array}{l}\text { Smoked } \\
\mathrm{N}(\%)\end{array}$ & $\begin{array}{l}\text { Smokeless } \\
\mathrm{N}(\%)\end{array}$ \\
\hline \multirow[t]{2}{*}{ Heavy alcohol consumption } & No & $2962(88.5)$ & $2473(92.7)$ & $489(72.2)$ & $413(72.3)$ & $211(64.7)$ \\
\hline & Yes & $384(11.5)$ & 196(7.3) & 188(27.8) & $158(27.7)$ & 115(35.3) \\
\hline \multirow[t]{3}{*}{ Physical activity level } & Low & $791(23.6)$ & $637(23.9)$ & $154(22.8)$ & 134(23.5) & $73(22.4)$ \\
\hline & Moderate & $405(12.1)$ & $358(13.4)$ & $47(7.0)$ & $31(5.4)$ & $26(8.0)$ \\
\hline & High & $2150(64.3)$ & $1674(62.7)$ & $476(70.3)$ & $406(71.1)$ & $227(69.6)$ \\
\hline \multirow[t]{2}{*}{ Khat chewing within 30 days } & Yes & $66(2.0)$ & $46(1.7)$ & $20(3.0)$ & $14(2.5)$ & $12(3.7)$ \\
\hline & No & $3280(98.0)$ & 2623(98.3) & 657(97.0) & $557(97.5)$ & $314(96.3)$ \\
\hline \multirow[t]{3}{*}{ Mental stress } & Mild & $2219(66.3)$ & 1790(67.1) & $429(63.4)$ & $356(62.3)$ & $202(62.0)$ \\
\hline & Moderate & $995(29.7)$ & $775(29.0)$ & $220(32.5)$ & 194(34.0) & 106(32.5) \\
\hline & Severe & $132(4.0)$ & 104(3.9) & $28(4.1)$ & $21(3.7)$ & $18(5.5)$ \\
\hline
\end{tabular}

was 21.8 (7.0) years. Related to the cessation of smoking, only $15.6 \%$ (89) of all smokers attempted to stop in the last 12 months. Three hundred twenty-six (9.7\%) used smokeless tobacco. Of those who use smokeless tobacco, 178 (54.6\%) use sniff tobacco and chewable tobacco together, and the remaining use only chewable tobacco. Of the smokeless tobacco users, 294 (90.2\%) use it daily. From the total, $543(16.2 \%)$ reported that there was someone in their home who smokes tobacco in the last 30 days.

\section{Factors associated with tobacco use}

The factors found to be significantly associated with current tobacco use were sex, age, occupation, educational status, wealth status, alcohol use and Khat chewing, physical activity level, mental stress level, and altitude. Current tobacco use was significantly lower among females (AOR 0.54; 95\%CI: 0.42-0.68). In a separate analysis, the prevalence of smoked and smokeless tobacco use among women had been nearly lower by 50\% (AOR 0.56, 95\% CI: 0.44-0.73 and AOR 0.54, 95\% CI: $0.40-0.74$, respectively) compared to men. The younger age group (25-35 years old) had significantly lower odds to use tobacco currently compared to older age groups (AOR for 35-44, 45-54, and 55-64 years old were 1.57 (95 CI: 1.14-2.17), 1.99(95\% CI: 1.45-2.74), and 3.26 (95\% CI: 2.37-4.48), respectively). The pattern is similar for smoked tobacco users. For smokeless tobacco use, the prevalence is only significantly higher for the age group 55-64 years (AOR 1.51; 95\% CI: $1.02-$ 2.23) compared with the younger age group (25-35 years old). There was significantly more tobacco use among farmers compared to other occupation (AOR 0.46; 95\%CI: 0.31-0.68). It is also similar to smoked tobacco use. For smokeless tobacco use, housewives had significantly lower odds (AOR 0.58; 95\%CI: 0.38-0.91) to being tobacco use compared with farmers. In addition, those participants with secondary and above (AOR 0.44; 95\%CI: 0.21-0.93) education were lower odds to use smokeless tobacco currently compared with those with no formal education. Those from the fifth quantile wealth index household had to be lower odds (AOR 0.61 ; $95 \%$ CI: $0.41-0.92$ ) to use smoked tobacco compared to the first quantile household. There is no difference among the wealth index groups for the current all form and smokeless tobacco use. Heavy alcohol consumption had nearly 4 times higher odds of being tobacco use (AOR of 3.97 (95\% CI: 3.07-5.12), 3.55 (95\% CI: 2.69-4.68), and 4.09 (95\% CI: 3.10-5.39) for all form, smoked, and smokeless, respectively) compared to their counterpart. Khat chewers had higher odds to use tobacco than non-chewers in different forms (AOR for all form, smoked, and smokeless were 3.07(95\%CI: $1.64-$ 5.77), 3.64(95\%CI: $1.73-7.66)$, and $2.22(95 \% \mathrm{CI}: 1.07-$ $4.59)$, respectively). The probability of use of tobacco reduces among those involved in moderate physical activities. This difference was significant for all form (AOR 0.65; 95\% CI: 0.44-0.96), and smoked (AOR 0.49; 95\% CI: $0.31-0.77)$ tobacco use. Those with severe mental stress had higher odds to use smokeless tobacco (AOR 1.79; 95\% CI: 1.02-3.14) than mild. Among participants, those who were living at highland use tobacco more than those who live in lowland in all form (AOR 4.39; 95\% CI: 3.216.01), smoked (AOR 6.79; 95\% CI: 4.68-9.85), and smokeless (AOR 1.90; 95\% CI: 1.28-2.81) (Table 3).

\section{Discussion}

Our findings indicate that the prevalence of current tobacco use among the study participants was $20.2 \%$. In addition, the prevalence of current smoked and smokeless tobacco use were 17.1 and $9.7 \%$, respectively. The national prevalence of cigarette smoking was $3.5 \%$ based 
Table 3 Multivariable logistic regression analysis of factors associated with current tobacco use among study participants ( $N=3346)$, Arba Minch HDSS, South Ethiopia

\begin{tabular}{|c|c|c|c|c|c|c|}
\hline \multirow[t]{3}{*}{ Categories } & \multicolumn{6}{|c|}{ Current Tobacco Use } \\
\hline & \multicolumn{2}{|c|}{ Smoked \& Smokeless } & \multicolumn{2}{|l|}{ Smoked } & \multicolumn{2}{|l|}{ Smokeless } \\
\hline & AOR $(95 \% \mathrm{Cl})$ & P-Value & AOR $(95 \% \mathrm{Cl})$ & P-Value & AOR $(95 \% \mathrm{Cl})$ & P-Value \\
\hline \multicolumn{7}{|l|}{ Sex } \\
\hline Male & Reference & & & & & \\
\hline Female & $0.54(0.42,0.68)^{*}$ & $<0.01$ & $0.56(0.44,0.73)^{*}$ & $<0.01$ & $0.54(0.40,0.74)^{*}$ & $<0.01$ \\
\hline \multicolumn{7}{|l|}{ Age group } \\
\hline $25-34$ & Reference & & & & & \\
\hline $35-44$ & $1.57(1.14,2.17)^{*}$ & 0.006 & $1.97(1.34,2.9)^{*}$ & 0.001 & $1.19(0.81,1.75)$ & 0.381 \\
\hline $45-54$ & $1.99(1.45,2.74)^{*}$ & $<0.01$ & $2.75(1.88,4.01)^{*}$ & $<0.01$ & $1.06(0.71,1.58)$ & 0.759 \\
\hline $55-64$ & $3.26(2.37,4.48)^{*}$ & $<0.01$ & $5.07(3.48,7.40)^{*}$ & $<0.01$ & $1.51(1.02,2.23) *$ & 0.038 \\
\hline \multicolumn{7}{|l|}{ Residency } \\
\hline Rural & Reference & & & & & \\
\hline Urban & $1.26(0.86,1.85)$ & 0.243 & $0.82(0.47,1.41)$ & 0.462 & $1.23(0.77,1.97)$ & 0.383 \\
\hline \multicolumn{7}{|l|}{ Marital status } \\
\hline Unmarried & Reference & & & & & \\
\hline Married & $1.09(0.77,1.55)$ & 0.624 & $1.04(0.70,1.55)$ & 0.853 & $0.95(0.60,1.52)$ & 0.839 \\
\hline \multicolumn{7}{|l|}{ Occupation } \\
\hline Farmer & Reference & & & & & \\
\hline Daily laborer & $0.87(0.56,1.35)$ & 0.537 & $0.88(0.52,1.48)$ & 0.62 & $0.66(0.36,1.21)$ & 0.178 \\
\hline Housewife & $0.88(0.65,1.19)$ & 0.407 & $0.83(0.60,1.16)$ & 0.283 & $0.58(0.38,0.91)^{*}$ & 0.017 \\
\hline Other@ & $0.66(0.43,0.99)^{*}$ & 0.045 & $0.55(0.33,0.9)$ & 0.019 & $0.65(0.39,1.09)$ & 0.106 \\
\hline \multicolumn{7}{|l|}{ Educational status } \\
\hline No formal education & Reference & & & & & \\
\hline Primary school & $0.94(0.70,1.27)$ & 0.697 & $1.00(0.70,1.43)$ & 0.994 & $0.72(0.49,1.04)$ & 0.081 \\
\hline Secondary \& above & $0.56(0.30,1.04)$ & 0.066 & $0.52(0.22,1.21)$ & 0.129 & $0.44(0.21,0.93)^{*}$ & 0.032 \\
\hline \multicolumn{7}{|l|}{ Wealth Index } \\
\hline 1st quantile & Reference & & & & & \\
\hline 2nd quantile & $1.02(0.78,1.34)$ & 0.891 & $1.04(0.78,1.40)$ & 0.773 & $0.99(0.69,1.42)$ & 0.945 \\
\hline 3rd quantile & $0.91(0.68,1.22)$ & 0.538 & $0.93(0.67,1.28)$ & 0.637 & $1.16(0.80,1.68)$ & 0.444 \\
\hline 4th quantile & $0.95(0.70,1.30)$ & 0.765 & $0.84(0.60,1.18)$ & 0.326 & $1.28(0.87,1.89)$ & 0.207 \\
\hline 5th quantile & $0.72(0.51,1.01)$ & 0.06 & $0.61(0.41,0.92)^{*}$ & 0.019 & $1.11(0.73,1.69)$ & 0.629 \\
\hline \multicolumn{7}{|c|}{ Heavy alcohol consumption } \\
\hline No & Reference & & & & & \\
\hline Yes & $3.97(3.07,5.12)^{*}$ & $<0.01$ & $3.55(2.69,4.68)^{*}$ & $<0.01$ & $4.09(3.10,5.39)^{*}$ & $<0.01$ \\
\hline \multicolumn{7}{|l|}{ Physical activity level } \\
\hline Low & Reference & & & & & \\
\hline Moderate & $0.65(0.44,0.96)^{*}$ & 0.029 & $0.49(0.31,0.77)^{*}$ & 0.002 & $0.79(0.48,1.29)$ & 0.344 \\
\hline High & $0.91(0.72,1.16)$ & 0.449 & $0.88(0.68,1.14)$ & 0.324 & $0.89(0.65,1.2)$ & 0.441 \\
\hline \multicolumn{7}{|c|}{ Khat chewing within 30 days } \\
\hline No & Reference & & & & & \\
\hline Yes & $3.07(1.64,5.77)^{*}$ & $<0.01$ & $3.64(1.73,7.66)^{*}$ & 0.001 & $2.22(1.07,4.59)^{*}$ & 0.031 \\
\hline \multicolumn{7}{|l|}{ Mental stress } \\
\hline Mild & Reference & & & & & \\
\hline
\end{tabular}


Table 3 Multivariable logistic regression analysis of factors associated with current tobacco use among study participants ( $N=3346)$, Arba Minch HDSS, South Ethiopia (Continued)

\begin{tabular}{|c|c|c|c|c|c|c|}
\hline \multirow[t]{3}{*}{ Categories } & \multicolumn{6}{|c|}{ Current Tobacco Use } \\
\hline & \multicolumn{2}{|c|}{ Smoked \& Smokeless } & \multicolumn{2}{|l|}{ Smoked } & \multicolumn{2}{|l|}{ Smokeless } \\
\hline & AOR $(95 \% \mathrm{Cl})$ & P-Value & AOR $(95 \% \mathrm{Cl})$ & P-Value & AOR $(95 \% \mathrm{Cl})$ & P-Value \\
\hline Moderate & $1.11(0.90,1.37)$ & 0.312 & $1.19(0.95,1.49)$ & 0.132 & $1.12(0.86,1.45)$ & 0.418 \\
\hline Severe & $1.49(0.91,2.45)$ & 0.115 & $1.44(0.81,2.55)$ & 0.216 & $1.79(1.02,3.14)^{*}$ & 0.043 \\
\hline \multicolumn{7}{|l|}{ Altitude } \\
\hline Lowland & Reference & & & & & \\
\hline Midland & $1.03(0.68,1.56)$ & 0.903 & $0.96(0.57,1.62)$ & 0.869 & $1.05(0.64,1.73)$ & 0.843 \\
\hline Highland & $4.39(3.21,6.01)^{*}$ & $<0.01$ & $6.79(4.68,9.85)^{*}$ & $<0.01$ & $1.9(1.28,2.81)^{*}$ & 0.001 \\
\hline
\end{tabular}

* Significant at P-Value $<0.05$

@ other include merchant, employee of the organizations, and unemployed

on the WHO report of 2017, 4.0\% based on the national STEPS survey of 2015, 4.1\% based on the Ethiopian DHS 2011 analysis, and 5.0\% based on the Global Adult Tobacco Survey of Ethiopia 2016 [3, 14-16], which are lower as compared to this finding. In addition, the Ethiopia DHS report of 2016 showed that 4.3 and $0.8 \%$ of men and women, respectively, use tobacco [28]. In 2009, a survey using the WHO STEPS approach in southwest Ethiopia showed that the prevalence of all forms of tobacco use was 9.3\% [34]. In general, tobacco use among the study population is higher compared to the national prevalence. A study conducted in eastern Ethiopia indicated that the proportion of current smokers was $28.6 \%$, which is higher compared to this finding [13]. Nearly one third (33.1\%) of pastoralists in the Borena zone, Ethiopia was daily use smokeless tobacco [18]. These significant differences might be related to the age group included in the study, and the difference in social norms and taboos regarding the use of tobacco. The global estimate of daily tobacco smoking was $15.2 \%$ in 2015 by Global Statistics on Addiction and $19.2 \%$ in 2017 by the WHO report on the Global Tobacco Epidemic [3, 7]. In addition, as it is also noted in a systematic review of tobacco smoking in sub-Saharan African countries, the smoking prevalence varies widely within the country [11]. This report also confirmed the significant variation in the prevalence of tobacco use in the country and this difference might be related to the difference in sociocultural norms.

In this study, the odds of all forms of tobacco use, smoked and smokeless tobacco use were significantly higher among men. This finding is similar to a study conducted in eastern Ethiopia, and national reports from Ethiopia including DHS (2011 and 2016), Global Adult Tobacco Survey (2016), NCD STEPS survey (2015) [13, $15,16,35]$. A systematic review of tobacco smoking for Sub-Saharan African countries showed that the prevalence of tobacco use is more prevalent among men participants [11]. In addition, different studies showed that there is a higher prevalence of tobacco use among men compared to women [36-39]. The higher number of tobacco use among men might be linked with the feature of sex roles in society. Men have had greater social power, which may result in restriction or prohibition of tobacco use among women, which were the major cause of gender difference in tobacco use [40].

The likelihood of current tobacco use increases among older age groups compared to the young age group. This was similar to smoked tobacco use. Even if the odds of smokeless tobacco use increase with age, the only significant increase in odds was observed among the age group from 55 to 64 years. It is similar to the analysis done based on the Swiss Health Survey, which indicated that the proportion of smoking was increased among the older age groups [36]. Similarly, a report based on the analysis of the DHS datasets for 30 sub-Saharan African countries and a separate analysis for Ethiopia indicated that the prevalence of smoking significantly higher among the older age groups $[35,39]$. This might relate to a delayed onset of tobacco use rather than the prevention of cigarette initiation [41]. A study conducted in Namibia indicated that the prevalence of smoking was higher among the age group of 20-29 years of age [42].

In this report, there was no significant difference in educational status regarding the use of tobacco, except for smokeless tobacco use. The odds of smokeless tobacco use significantly reduces with increasing educational levels. Consistent with the finding of this study, an analysis for 30 sub-Saharan African countries showed that the likelihood of smokeless tobacco use was higher among the uneducated group compared to the educated group. It also indicated that smoking had a weak relationship with education [39]. A study in Mumbai, India showed that the likelihood of smokeless tobacco use was inversely related to education level [43], which is similar to this finding. In addition, reports based on 2008-2010 Global Adult Tobacco Surveys indicated that the prevalence of tobacco use is higher among less educated [44, 45]. Even if it is not 
only for smokeless tobacco use, other studies also reported similarly that individuals with higher education were less likely to smoke tobacco $[35,36,43]$.

Even if there was a gradient reduction in the odds of tobacco use across the wealth index in this study, there was no significant difference for all forms of tobacco use. However, the likelihood of smoked tobacco use was significantly lower among higher wealth index individuals (the fifth quantile compared to the first quantile). Analysis based on Ethiopian DHS of 2011 and 2016 indicated that smoking is significantly lower among individuals from higher household wealth [35]. Reports based on 2003 the World Health Survey of 48 Low- and Middle-Income Countries and Global Adult Tobacco Survey (based on 2008-2012) indicated that wealth status is a significant determinant of smoking risk. They showed that the prevalence of tobacco use is higher among low economic groups [44-46]. In addition to the high prevalence of smoking among individuals from lower socioeconomic, they smoke for longer durations than others [47]. The long duration of smoking may lead to experience financial stress and a deterioration of standards of living for longer periods of time. On top of the negative effect of tobacco use on health status, it will likely exacerbate existing health inequalities $[5,6,47]$.

In this study, the odds of tobacco use was significantly higher among heavy episodic drinkers. Studies indicated that those who drink are very likely to smoke and these behaviors are highly correlated behaviors [48-52]. The use of heavy episodic drink of alcohol increases the probability of smoking and vice versa. In addition, both tobacco and alcohol use tend to be used together, for instance in times of stress [53].

Khat (Catha edulis) is a chewable fresh leave which contains amphetamine-like stimulatory and commonly used in East Africa [54, 55]. In this study, the odds of all forms of tobacco use and smoked and smokeless tobacco use were significantly higher among khat chewers. Different studies indicated that the proportion of tobacco use increase among khat users. Ethiopian NCD STEPS survey of 2015, and analysis based on Ethiopian DHS of 2011 and 2016, indicated that khat chewing is associated with tobacco use [15, 35]. In addition, a correctional study to see the correlation of concurrent khat and tobacco use in Yemen showed positive associations between khat and tobacco use [37]. A systematic review of the epidemiology of tobacco use and khat users concluded that the prevalence of tobacco use among khat users appears significantly higher [56]. It is expected that smoking helps to heighten the stimulant effect to khat and to break the negative psychological state [13] and the phenomena used to explain the association of alcohol and tobacco may be used for khat also [53].
The odds of all forms of tobacco and smoked tobacco use were significantly higher among those participants with moderate physical activity levels compared to lower physical activity levels. There is no significant difference in the use of smokeless tobacco. An analysis of the health survey of England indicated that individuals involving in sports activity were less likely to smoke. While distinguishing the type of physical activity by occupation or sport club-related physical activities, smoking was less common among sports-club members [57]. It is also indicated that smokers had low leisure-time physical activity [36].

In this study, the odds of smokeless tobacco use was significantly higher among severe mental stress participants compared to mild mental stress. Even if it is not significant, the odds of all forms of tobacco use increase with stress level. An experimental study indicated that stress significantly increases cigarette craving but did not increase smoking [58]. A study on smokeless tobacco and USA military deployment indicated that stress among the military associated with an increased risk of smokeless tobacco initiation [59]. A review of stress and tobacco use indicated a strong link between tobacco use and stress level. High-stress level predisposes for greater vulnerability for tobacco use [60].

The odds of tobacco use was significantly higher among those living in highland compared to lowlanders. This result is similar for smoked and smokeless tobacco use in a separate analysis. A study among Colombian Medical Schools showed that an increase in the prevalence of smoking with altitude [61]. A study based on a median altitude of state residents of the USA on chronic obstructive pulmonary disease mortality on a role for altitude showed that there is no association between altitude and smoking [62]. Increasing smoking prevalence at high altitudes is a serious public health issue since altitude aggravates at least some of the effects of smoking. An increase in the volume of red blood cells, a mechanism for coping with oxygen shortage at a higher altitude, was higher for non-smokers and respiratory function was for smokers who live in highland compared to lowland [63]. Opposite to the finding of this, an analysis based on Ethiopian DHS (2011 and 2016) indicated that the prevalence of tobacco smoking is significantly higher among lowlanders compared to highlanders [35]. The analysis based on Ethiopian DHS (2011 and 2016), noted that altitude information is missing for 47 community clusters.

We follow a standardized method and tool, which was described in the WHO STEPS guideline. This makes our finding easy to compare with studies conducted based on a similar method and definition of tobacco use. In this study, we consider three outcome variables of tobacco use for analysis, which are all form (smoked and/ 
or smokeless), smoked and smokeless tobacco use, to see their association with independent variables. Because of the cross-sectional nature of the study, it is difficult to determine which comes first in variables like tobacco use and stress level, khat chewing, and heavy episodic drink of alcohol.

Tobacco use is significantly different in different parts of the country. The national and pocket study reports have a huge difference in the prevalence of tobacco use. The finding of this report is higher than the national reports. To uncover the differences in the use of tobacco, the national reports need to be disaggregated. On top of this, it is important to investigate the reason for the differences in the prevalence of tobacco use. In addition, the implementation of policies for combating tobacco use in Ethiopia needs to account for the local contexts of tobacco use prevalence. Further, the reason for the use of smokeless tobacco among severe mental stress level needs to be explored.

\section{Conclusions}

Nearly one in five adults use tobacco currently in the study area, which is more than the national reports. In addition, nearly 17 and $10 \%$ use smoked and smokeless tobacco currently, respectively. Sex, age, heavy alcohol consumption, physical activity level, khat chewing and altitude of their residency were associated with tobacco use. Interventions for the reduction of tobacco use need to give due attention to men, older adults, uneducated, lower socio-economic status, and highlanders. Intervention on the reduction of heavy alcohol consumption and khat chewing may have an impact on tobacco use.

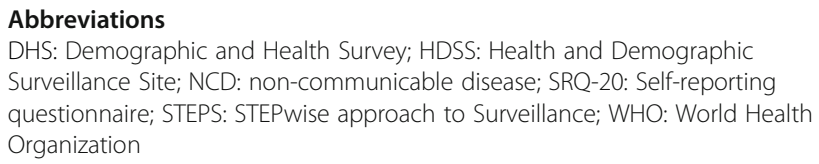

\section{Acknowledgments}

We thank the respondents, field and data entry staff of the Arba Minch HDSS for their respective contributions to the production of the data used in this study. We acknowledge Arba Minch Demographic Surveillance and Health Research Center, Arba Minch University for providing sampling frame and supporting data collection, entry and analysis.

\section{Authors' contributions}

BTG, AC, and GA conceptualized this analysis, with input from all co-authors. $B T G$ led the analysis design and prepared the draft manuscript. AC, GA, WE, ZAM, EZT, ZZ, AB and NDM provided critical comments towards the interpretation of results and drafted portions of the manuscript. All authors read and approved the final manuscript.

\section{Funding}

This study was funded by Arba Minch Demographic Surveillance and Health Research Center, Arba Minch University.

\section{Availability of data and materials}

The datasets used and/or analyzed during the current study are available from the corresponding author upon reasonable request.

\section{Ethics approval and consent to participate}

Ethical approval was obtained from the Institutional Review Board of Arba Minch University. A formal letter was written to different administrative bodies and organizations to get permission to conduct the research within the settings. The informed consent obtained from study participants before the interview was verbal and approved by the ethical committee of the Institutional Research Ethics Review Board of Arba Minch University. The privacy of the study participants was maintained by interviewing the participants alone. Ethical approval for all procedures including the data collection method and verbal consent was obtained from the Institutional Review Board of Arba Minch University.

\section{Consent for publication}

Not applicable.

\section{Competing interests}

The authors declare that they have no competing interests.

\section{Author details}

${ }^{1}$ School of Public Health, Arba Minch University, P.O.Box 21, Arba Minch, Ethiopia. ${ }^{2}$ Arba Minch Health and Demographic Surveillance Site (HDSS), Arba Minch, Ethiopia. ${ }^{3}$ CARE Ethiopia Hawassa Project Office, Hawassa, Ethiopia. ${ }^{4}$ School of Nursing, Arba Minch University, Arba Minch, Ethiopia. ${ }^{5}$ Department of Medical Laboratory Science, Arba Minch University, Arba Minch, Ethiopia. ${ }^{6}$ Department of Computer Science, Arba Minch University, Arba Minch, Ethiopia.

Received: 21 May 2020 Accepted: 22 February 2021

Published online: 04 March 2021

\section{References}

1. Gupta PC, Pednekar MS, Parkin DM, Sankaranarayanan R. Tobacco associated mortality in Mumbai (Bombay) India. Results of the Bombay cohort study. Int J Epidemiol. 2005;34(6):1395-402.

2. World Health Organization: WHO report on the global tobacco epidemic, 2017: monitoring tobacco use and prevention policies: World Health Organization; 2017.

3. World Health Organization: WHO Report on the Global Tobacco Epidemic, 2019. In Geneva: World Health Organization; 2019.

4. Z Zheng W, McLerran DF, Rolland BA, Fu Z, Boffetta P, He J, Gupta PC, Ramadas K, Tsugane S, Irie F, et al. Burden of Total and cause-specific mortality related to tobacco smoking among adults aged $\geq 45$ years in Asia: a pooled analysis of 21 cohorts. PLoS Med. 2014;11(4):e1001631.

5. Eriksen M, Mackay J, Ross H: The tobacco atlas. 4 [3] th Ed. Atlanta, GA: American 2012

6. World Health Organization: Systematic review of the link between tobacco and poverty - 2014 update. World Health Organization 2011.

7. Peacock A, Leung J, Larney S, Colledge S, Hickman M, Rehm J, Giovino GA, West R, Hall W, Griffiths P, et al. Global statistics on alcohol, tobacco and illicit drug use: 2017 status report. Addiction. 2018;113(10):1905-26.

8. Mackay J, Eriksen M: The tobacco atlas: World Health Organization 2002. In.

9. Misganaw A, Haregu TN, Deribe K, Tessema GA, Deribew A, Melaku YA, Amare AT, Abera SF, Gedefaw M, Dessalegn M. National mortality burden due to communicable, non-communicable, and other diseases in Ethiopia, 1990-2015: findings from the global burden of disease study 2015. Popul Health Metrics. 2017;15(1):1-17.

10. World Health Organization: WHO global report on trends in prevalence of tobacco smoking 2000-2025. 2018.

11. Brathwaite R, Addo J, Smeeth L, Lock K. A systematic review of tobacco smoking prevalence and description of tobacco control strategies in subSaharan African countries; 2007 to 2014. PLoS One. 2015;10(7):e0132401.

12. Öberg M, Jaakkola MS, Woodward A, Peruga A, Prüss-Ustün A. Worldwide burden of disease from exposure to second-hand smoke: a retrospective analysis of data from 192 countries. Lancet. 2011;377(9760):139-46.

13. Reda AA, Kotz D, Biadgilign S. Adult tobacco use practice and its correlates in eastern Ethiopia: a cross-sectional study. Harm Reduct J. 2013;10(1):28.

14. Lakew $Y$, Haile D. Tobacco use and associated factors among adults in Ethiopia: further analysis of the 2011 Ethiopian demographic and health survey. BMC Public Health. 2015;15(1):487.

15. Defar A, Getachew T, Teklie H, Bekele A, Gonfa G, Gelibo T, Amenu K, Tadele $T$, Taye $G$, Getinet $M$ et al: Tobacco use and its predictors among 
Ethiopian adult: A further analysis of Ethiopian NCD STEPS survey-2015. Ethiopian Journal of Health Development 2017, 31(Specialissue1):331-339.

16. Gats: Global adult tobacco survey Fact sheet Ethiopia: 2016. In.; 2016: 1-2.

17. Sabit Abazinab ND. Prevalence and Predictors of Cigarette Smoking among Adolescents of Ethiopia: School Based Cross Sectional Survey. Journal of Child and Adolescent Behaviour. 2015:03(01).

18. Etu ES, Gemeda DH, Hussen MA. Prevalence and factors that influence smokeless tobacco use among adults in pastoralist communities of Borena zone, Ethiopia: mixed method study. Tob Induc Dis. 2017;15(1):1-1.

19. Petersen AB, Thompson LM, Cataldo JK. Tobacco use and secondhand smoke exposure among women in Aleta Wondo, Ethiopia: a cross-sectional study. Annals of Global Health. 2016;82(3):520.

20. World Health Organization: WHO Report on the Global Tobacco Epidemic, 2008 The MPOWER package: World Health Organization; 2008.

21. Asma S, Mackay J, Yang Song S, et al.: The GATS atlas. Global Adult Tobacco Survey CDC Foundation 2015:30-31.

22. Forouzanfar MH, Afshin A, Alexander LT, Biryukov S, Brauer M, Cercy K, Charlson FJ, Cohen AJ, Dandona L, Estep K, et al. Global, regional, and national comparative risk assessment of 79 behavioural, environmental and occupational, and metabolic risks or clusters of risks, 1990-2015: a systematic analysis for the global burden of disease study 2015. Lancet. 2016;388(10053):1659-724.

23. World Health Organization: The WHO STEPwise approach to Surveillance of noncommunicable diseases (STEPS): A framework for surveillance. In Edited by World Health Organization NDaMH; 2003: 1-50.

24. Indepth Network: Population and Health in Developing Countries: Population, Health, and Survival at INDEPTH Sites, vol. 1: IDRC, Ottawa, ON, CA; 2002

25. Helelo TP, Gelaw YA, Adane AA. Prevalence and associated factors of hypertension among adults in Durame town, Southern Ethiopia. PLOS ONE. 2014:9(11):e112790.

26. World Health Organization: The WHO STEPwise approach to noncommunicable disease risk factor surveillance. In.: Geneva: World Health Organization; 2005.

27. Beusenberg M, Orley J: A user's guide to the self reporting questionnaire (SRQ). In: Geneva: World Health Organization; 1994: 84.

28. CSA, ICF: Ethiopia demographic and health survey. In. Addis Ababa, Ethiopia, and Rockville, Maryland, USA: Ethiopia Central Statistical Agency and ICF; 2016.

29. Gutema BT, Chuka A, Kondale M, Ayele G, Kote M, Zerdo Z, Merdekios B, Tsala T, Baharu A, Ukke GG. The burden of malnutrition among adults residing in Arba Minch health and demographic surveillance site (HDSS): a WHO STEPS survey. Journal of Nutrition and Metabolism. 2020;2020.

30. Chuka A, Gutema BT, Ayele G, Megersa ND, Melketsedik ZA, Zewdie TH. Prevalence of hypertension and associated factors among adult residents in Arba Minch health and demographic surveillance site, Southern Ethiopia. PloS one. 2020;15(8):e0237333.

31. Gutema BT, Chuka A, Ayele G, Tariku EZ, Aschalew Z, Baharu A, Degefa N, Gurara MK. Prevalence of heavy episodic drinking and associated factors among adults residing in Arba Minch health and demographic surveillance site: a cross sectional study. BMC Public Health. 2020;20(1):1-8.

32. MoA: Agro-Ecological Zones of Ethiopia. In.: Natural Resources Management and Regulatory Department, Ministry of ...; 1998.

33. World Health Organisation: Global status report on alcohol and health: World Health Organization; 2011.

34. Alemseged F, Haileamlak A, Tegegn A, Tessema F, Woldemichael K, Asefa M, Mamo Y, Tamiru S, Abebe G. Risk factors for chronic non-communicable diseases at gilgel gibe field research center, Southwest Ethiopia: population based study. Ethiop J Health Sci. 2012;22(S):19-28.

35. Guliani $\mathrm{H}$, Gamtessa S, Çule M. Factors affecting tobacco smoking in Ethiopia: evidence from the demographic and health surveys. BMC Public Health. 2019;19(1):938.

36. Chiolero A, Wietlisbach V, Ruffieux C, Paccaud F, Cornuz J. Clustering of risk behaviors with cigarette consumption: a population-based survey. Prev Med. 2006;42(5):348-53.

37. Nakajima M, Dokam A, Khalil NS. Alsoofi M, al'Absi M: correlates of concurrent Khat and tobacco use in Yemen. Subst Use Misuse. 2016;51(12):1535-41.

38. Rudatsikira E, Abdo A, Muula AS. Prevalence and determinants of adolescent tobacco smoking in Addis Ababa, Ethiopia. BMC Public Health. 2007;7(1):176.

39. Sreeramareddy CT, Pradhan MM, Sin S. Prevalence, distribution, and social determinants of tobacco use in 30 sub-Saharan African countries. BMC Med. 2014;12(1):243

40. Waldron I, Bratelli G, Carriker L, Sung WC, Vogeli C, Waldman E. Gender differences in tobacco use in Africa, Asia, the Pacific, and Latin America. Soc Sci Med. 1988;27(11):1269-75.
41. Barrington-Trimis JL, Braymiller JL, Unger JB, McConnell R, Stokes A, Leventhal AM, Sargent JD, Samet JM, Goodwin RD. Trends in the age of cigarette smoking initiation among young adults in the US from 2002 to 2018. JAMA Netw Open. 2020;3(10):e2019022.

42. He Z, Bishwajit $G$, Yaya S. Prevalence of alcohol and tobacco use among men and women in Namibia. Int J Environ Res Public Health. 2019;16(1):59.

43. Sorensen G, Gupta PC, Pednekar MS. Social disparities in tobacco use in Mumbai, India: the roles of occupation, education, and gender. Am J Public Health. 2005;95(6):1003-8.

44. Tee GH, Aris T, Rarick J, Irimie S. Social determinants of health and tobacco use in five low - and middle-income countries - results from the global adult tobacco survey (GATS), 2011-2012. Asian Pac J Cancer Prev. 2016;17(3):1269-76.

45. Palipudi KM, Gupta PC, Sinha DN, Andes $\sqcup$, Asma S, McAfee T. Social determinants of health and tobacco use in thirteen low and middle income countries: evidence from global adult tobacco survey. PLoS One. 2012;7(3):e33466.

46. Hosseinpoor AR, Parker LA, Tursan d'Espaignet E, Chatterij S. Socioeconomic inequality in smoking in low-income and middle-income countries: results from the world health survey. PLoS One. 2012;7(8):e42843.

47. Siahpush M, Singh GK, Jones PR, Timsina LR. Racial/ethnic and socioeconomic variations in duration of smoking: results from 2003, 2006 and 2007 tobacco use supplement of the current population survey. Public Health. 2010;32(2):210-8.

48. Gupta PC, Maulik PK, Pednekar MS, Saxena S. Concurrent alcohol and tobacco use among a middle-aged and elderly population in Mumbai. Natl Med J India. 2005;18(2):88-91.

49. Paavola M, Vartiainen E, Haukkala A. Smoking, alcohol use, and physical activity: a 13-year longitudinal study ranging from adolescence into adulthood. J Adolesc Health. 2004;35(3):238-44.

50. De Leon J, Rendon DM, Baca-Garcia E, Aizpuru F, Gonzalez-Pinto A, Anitua C, Diaz FJ. Association between smoking and alcohol use in the general population: stable and unstable odds ratios across two years in two different countries. Alcohol Alcohol. 2007:42(3):252-7.

51. Falk DE, Yi HY, Hiller-Sturmhöfel $\mathrm{S}$. An epidemiologic analysis of cooccurring alcohol and tobacco use and disorders: findings from the National Epidemiologic Survey on alcohol and related conditions. Alcohol Res Health. 2006;29(3):162-71.

52. Drobes DJ. Concurrent alcohol and tobacco dependence mechanisms and treatment. Alcohol Res Health. 2002;26(2):136-42.

53. Shiffman S, Balabanis M: Associations between alcohol and tobacco. National Institute of Alcohol Abuse and Alcoholism Research Monograph No 30: Alcohol and tobacco: From basic science to clinical practice 1995, 30:17-36.

54. Al-Hebshi N, Skaug N. Khat (Catha edulis)—an updated review. Addict Biol. 2005;10(4):299-307.

55. Widler P, Mathys K, Brenneisen R, Kalix P, Fisch HUU. Pharmacodynamics and pharmacokinetics of khat: a controlled study. Clinical Pharmacology \& Therapeutics. 1994;55(5):556-62.

56. Kassim S, Jawad M, Croucher R, Akl EA. The epidemiology of tobacco use among khat users: a systematic review. Biomed Res Int. 2015;2015.

57. Poortinga W. Associations of physical activity with smoking and alcohol consumption: a sport or occupation effect? Prev Med. 2007;45(1):66-70.

58. Childs $\mathrm{E}$, de Wit $\mathrm{H}$. Effects of acute psychosocial stress on cigarette craving and smoking. Nicotine and Tobacco Research. 2010;12(4):449-53.

59. Hermes EDA, Wells TS, Smith B, Boyko EJ, Gackstetter GG, Miller SC, Smith TC. Smokeless tobacco use related to military deployment, cigarettes and mental health symptoms in a large, prospective cohort study among US service members. Addiction. 2012;107(5):983-94.

60. Torres OV, O'Dell LE. Stress is a principal factor that promotes tobacco use in females. Prog Neuro-Psychopharmacol Biol Psychiatry. 2016;65:260-8.

61. Rosselli D, Rey O, Calderon C, Rodriguez MN. Smoking in Colombian medical schools: the hidden curriculum. Prev Med. 2001:33(3):170-4.

62. Coté TR, Stroup DF, Dwyer DM, Horan JM, Peterson DE. Chronic obstructive pulmonary disease mortality: a role for altitude. Chest. 1993;103(4):1194-7.

63. Q-q P, Basang Z, Cui C-Y, Li L, Qian J, Gesang Q, Yang L, La Z, De Y, Dawa P. Physiological responses and evaluation of effects of BMl, smoking and drinking in high altitude acclimatization: a cohort study in Chinese Han young males. PLoS One. 2013;8(11):e79346.

\section{Publisher's Note}

Springer Nature remains neutral with regard to jurisdictional claims in published maps and institutional affiliations. 